Article

\title{
The Effects of in Situ-Formed Silver Nanoparticles on the Electrical Properties of Epoxy Resin Filled with Silver Nanowires
}

\author{
Gwang-Seok Song ${ }^{1}$, Dai Soo Lee ${ }^{1, *}$ and Ilho Kang ${ }^{2, *}$ \\ 1 Division of Semiconductor and Chemical Engineering, Chonbuk National University, Baekjedaero 567, \\ Deokjin-gu, Jeonju, Chonbuk 54896, Korea; michaelis@naver.com \\ 2 Research Center, NEPES AMC, 99 Seokam-ro, Iksan, Chonbuk 54587, Korea \\ * Correspondence: daisoolee@jbnu.ac.kr (D.S.L.); kangilho@nepesamc.co.kr (I.K.); \\ Tel.: +82-63-270-2310 (D.S.L.); +82-63-833-2020 (I.K.)
}

Academic Editor: Frank Wiesbrock

Received: 23 February 2016; Accepted: 15 April 2016; Published: 21 April 2016

\begin{abstract}
A novel method for preparing epoxy/silver nanocomposites was developed via the in situ formation of silver nanoparticles (AgNPs) within the epoxy resin matrix while using silver nanowires (AgNWs) as a conductive filler. The silver-imidazole complex was synthesized from silver acetate (AgAc) and 1-(2-cyanoethyl)-2-ethyl-4-methylimidazole (imidazole). AgNPs were generated in situ during the curing of the epoxy resin through the thermal decomposition of the AgAc-imidazole complex, which was capable of reducing $\mathrm{Ag}^{+}$to $\mathrm{Ag}$ by itself. The released imidazole acted as a catalyst to cure the epoxy. Additionally, after the curing process, the in situ-generated AgNPs were stabilized by the formed epoxy network. Therefore, by using the thermal decomposition method, uniformly dispersed AgNPs of approximately $100 \mathrm{~nm}$ were formed in situ in the epoxy matrix filled with AgNWs. It was observed that the nanocomposites containing in situ-formed AgNPs exhibited isotropic electrical properties in the epoxy resins in the presence of AgNWs.
\end{abstract}

Keywords: in situ-formed silver nanoparticles; silver nanowire; epoxy resin; nanocomposite

\section{Introduction}

Nanocomposite materials containing metal nanoparticles, graphenes, or organoclays dispersed into a polymer matrix exhibit significant absorbing properties because of their novel physical and chemical properties [1-3]. Specifically, epoxy/metal nanocomposites were used in the field of microelectronic packaging for applications in embedded capacitors and lead-free interconnecting materials [4-7]. One-dimensional nanostructured particles such as nanowires, nanotubes, nanorods, or nanofibers are expected to play an important role in fabricating nanoscale devices and nanocomposites. Metal nanowires such as silver nanowires (AgNWs) were employed as conductive fillers [8-16]. AgNWs have very low electrical resistivity and high thermal conductivity. Consequently, AgNWs have been primarily used as conductive fillers in conductive adhesive materials. An appropriate distribution of AgNWs within the epoxy network is very important for these applications. However, AgNWs are thermodynamically unstable and tend to form agglomerates because of their surface activity. Agglomeration occurs, and the anisotropic performance of AgNWs by the aspect ratio is a significant problem when NWs are used to fabricate composites with high performance. Polymeric stabilizing agents, such as poly(vinylpyrrolidone), poly(ethyleneglycol), and other long-chain acids or amines, are usually introduced in the chemical syntheses of AgNWs to prevent agglomerate formation [17-25]. However, these stabilizing agents are seldom removed from the AgNW surfaces because of the strong interaction between them. These residues of organic molecules on NW surfaces are harmful, as they reduce electrical resistivity. Therefore, their application in electronic packaging is limited [26]. 
A uniform dispersion of AgNWs in nanocomposites is required as clumps of wires inside the polymer matrix lead to undesirable electrical, dielectric, and thermal properties. However, it is difficult to achieve uniformly dispersed ultrafine NWs in a polymer matrix by incorporating pre-added AgNWs into a polymer. This is because of the easy agglomeration of NWs and high viscosity of polymer systems with AgNWs. Conversely, the in situ formation of silver nanoparticles (AgNPs) in a polymer matrix could facilitate a more uniform dispersion of AgNWs in polymers. Further, in situ reduction can result in much smaller particle sizes than the commercially available micron or nano size silver particles. This, in turn, can help achieve electrical conductivity for the encapsulants and adhesives.

In this study, a novel method for preparing epoxy/silver nanocomposites was investigated. The method involved forming in situ AgNPs via the decomposition of a silver-imidazole complex with AgNWs and the curing of an epoxy resin. At a suitable curing temperature, the AgNP was formed in situ in the nanocomposites of the epoxy resin and in the AgNW by the decomposition of the silver-imidazole complex, which was capable of reducing $\mathrm{Ag}^{+}$to $\mathrm{Ag}$ by itself. Imidazole was immediately released from the silver-imidazole complex and could act as an epoxy resin catalyst. Specifically, the anisotropic properties of the nanocomposites due to the high aspect ratio of AgNWs disappeared because of the in situ-formed AgNP.

\section{Materials and Methods}

\subsection{Materials}

Silver nitrate $\left(\mathrm{AgNO}_{3}\right)$, chloroplatinic acid $\left(\mathrm{H}_{2} \mathrm{PtCl}_{6} \cdot 6 \mathrm{H}_{2} \mathrm{O}\right)$, poly(vinylpyrrolidone) (PVP), anhydrous ethylene glycol (EG), and sodium chloride $(\mathrm{NaCl})$ were purchased from Sigma Aldrich Chemical (Yongin, Kyeonggi-do, Korea) for the syntheses of AgNWs. A cycloaliphatic-type epoxy resin was purchased from Daicel Chemical Industry (Minato-ku, Tokyo, Japan). The anhydride-type curing agent, hexahydro-4-methylphthalic anhydride, and silver acetate (AgAc) were purchased from Sigma Aldrich Chemical. An imidazole-type catalyst, 1-(2-cyanoethyl)-2-ethyl-4-methylimidazole (imidazole), was purchased from TCI Chemical (Chuo-ku, Tokyo, Japan). The synthesized AgNW was purified using the washing method. Isopropyl alcohol (IPA), purchased from SK Chemical (Seongnam-si, Kyeonggi-do, Korea), was chosen as the solvent because of its low boiling point and capacity as a good stabilizer for AgNWs.

\subsection{Synthesis of Silver Nanowires (AgNWs) Using a Microwave Process}

The microwave polyol process used in this study was the same as that in the literature [27]. The solution containing $\mathrm{AgNO}_{3}, \mathrm{H}_{2} \mathrm{PtCl}_{6} \cdot 6 \mathrm{H}_{2} \mathrm{O}, \mathrm{PVP}$ (average molecular weight: $55,000 \mathrm{~g} / \mathrm{mol}$ ), and $\mathrm{NaCl}$ in EG was irradiated using a microwave oven (LG electronics, Yeongdeungpo-gu, Seoul, Korea) in continuous wave mode at $700 \mathrm{~W}$. The solution was rapidly heated within $2 \mathrm{~min}$, and an AgNW was formed. The AgNW was washed with acetone and dispersed in IPA.

\subsection{Preparation of Silver-Imidazole Complex}

Silver acetate (AgAc, $3 \mathrm{mmol}$ ) was added to imidazole $(6 \mathrm{mmol})$. A paste mixer was used to dissolve the mixture until all the solid AgAc had dissolved. The liquid product had a yellow color and was viscous at $25^{\circ} \mathrm{C}$.

\subsection{Preparation of Epoxy/Silver Nanocomposites with AgNWs}

The $10 \mathrm{wt} \%$ of silver-imidazole complex was dispersed in the epoxy resin. The molar ratio of AgAc to imidazole was maintained at 1:2. A purified AgNW in IPA was added to the above mixture and was mixed until a light-yellow solution was formed. The solvent was evaporated under reduced pressure at $40^{\circ} \mathrm{C}$. Finally, the mix was cured at $110^{\circ} \mathrm{C}$ for $30 \mathrm{~min}, 150{ }^{\circ} \mathrm{C}$ for $2.5 \mathrm{~h}$, and $180^{\circ} \mathrm{C}$ for $1 \mathrm{~h}$ to obtain epoxy/silver nanocomposites. The thermal decomposition of silver-imidazole complex realized the formation of AgNPs. The silver-imidazole complex was capable of reducing $\mathrm{Ag}^{+}$to $\mathrm{Ag}$ 
under the stepwise curing condition of the epoxy. Scheme 1 shows the synthesis process of AgNPs via the decomposition of the silver-imidazole complex [28]. This was confirmed using thermogravimetric analysis (TGA), field electron scanning electron microscopy (FE-SEM), and energy-dispersive X-ray spectroscopy (EDX) analysis. This study investigated various epoxy/silver nanocomposites with different AgNW loading levels.

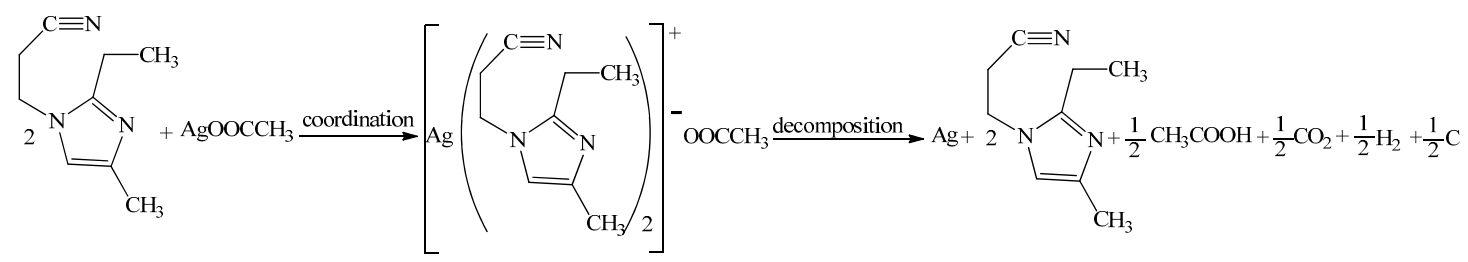

Scheme 1. Scheme for the silver nanoparticles (AgNPs) formed by in situ thermal decomposition of silver-imidazole complex.

The released imidazole in Scheme 1 acted as a catalyst for the curing of the epoxy resin. It was confirmed in DSC that the scanning of the epoxy resin containing anhydride-type curing agent and the silver-imidazole complex accompanied an exotherm due to the cure reaction, while the epoxy resin with only the anhydride-type curing agent without the silver-imidazole complex did not, as shown in Figure S1 in Supplementary Materials.

\subsection{Characterization}

The morphology of AgNWs was recorded using a transmission electron microscope (JEM-2010, JEOL, Akishima, Tokyo, Japan) and scanning electron microscope (JSM-5900, JEOL). The standard copper grid for the TEM image was dipped in the dispersion of a $0.1 \%$ AgNW in IPA for transmission electron microscopy (TEM) imaging. The fracture surfaces of the nanocomposite samples were observed under a field emission scanning electron microscope (S-4800, HITACHI, Minato-ku, Tokyo, Japan) after cryogenic fracture. The electrical properties of the nanocomposites were studied by measuring the surface resistivity of the composite sheets with a resistivity meter (ST-4, SIMCO JAPAN, Inc., Chuo-ku, Kobe, Japan) at room temperature. The TGA samples (Q50, TA Instruments, New Castle, DE, USA) were heated at a rate of $10^{\circ} \mathrm{C} / \mathrm{min}$ up to $800^{\circ} \mathrm{C}$ under a nitrogen atmosphere to measure the amount of in situ-formed AgNPs.

\section{Results and Discussion}

Figure 1 displays a TEM micrograph and a histogram for the diameter of the AgNWs synthesized via the microwave process. The average diameter of the NWs was $80 \mathrm{~nm}$. Figure 2 shows the SEM image and a histogram for the length of AgNWs after purification for removing the AgNPs from the synthesized sample. The average length of the NWs was $12.5 \mu \mathrm{m}$. Table 1 shows the EDX data for the cured epoxy/silver nanocomposite with a $10 \mathrm{wt} \%$ silver-imidazole complex. The epoxy/silver nanocomposite cured with the silver-imidazole complex had $3.29 \mathrm{wt} \%$ silver particles. The silver-imidazole-cured epoxy nanocomposite contained silver atoms. In contrast, the imidazole-cured nanocomposite did not contain silver atoms. Figure 3 shows the TGA thermograms of the imidazole, AgAc, and the silver-imidazole complex. It should be noted that $26 \mathrm{wt} \%$ silver was formed by the decomposition of the silver-imidazole complex. It was assumed that the AgNPs were formed in situ via the decomposition of the silver-imidazole complex during the curing of the epoxy resin. It is of interest to note that the silver content measured by EDX for the epoxy resin cured with the $10 \mathrm{wt} \%$ silver-imidazole complex was $3.29 \mathrm{wt} \%$, which was higher than that expected, i.e., $2.6 \mathrm{wt} \%$, considering that $26 \mathrm{wt} \%$ silver was formed by the decomposition of the silver-imidazole complex in TGA. It is speculated that the silver content measured by EDX reflects silver atoms in the surface of protruded silver nanoparticles in the fracture surface and can be higher than the silver content based on the TGA thermogram. 


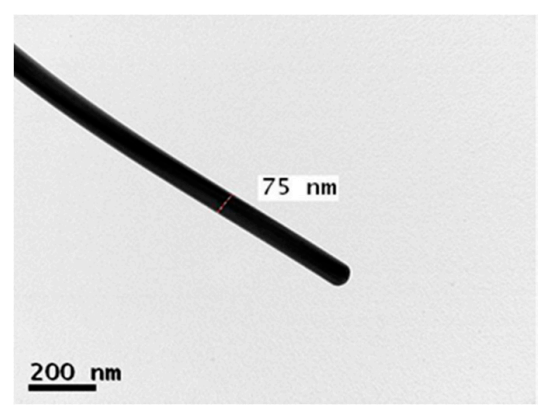

(a)

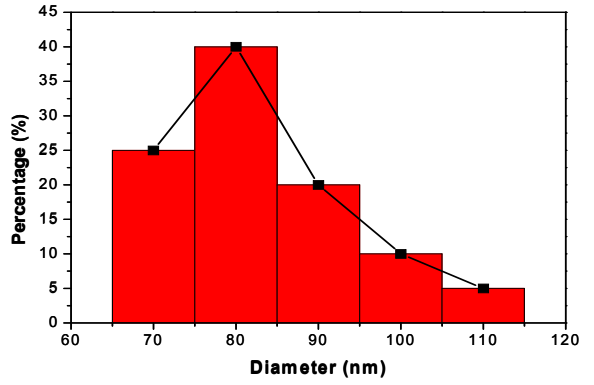

(b)

Figure 1. Synthesized silver nanowires (AgNWs): (a) transmission electron microscopy image; (b) diameter distribution of the purified AgNW.

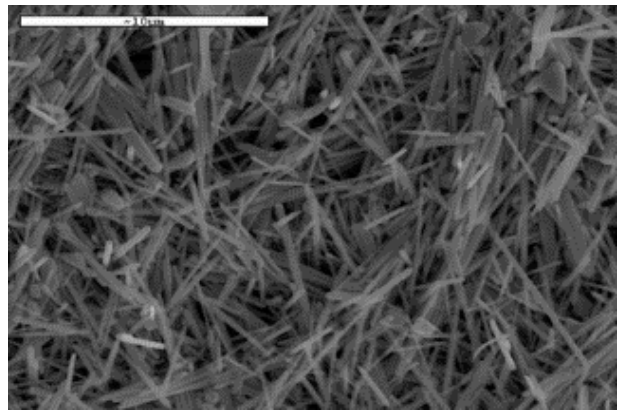

(a)

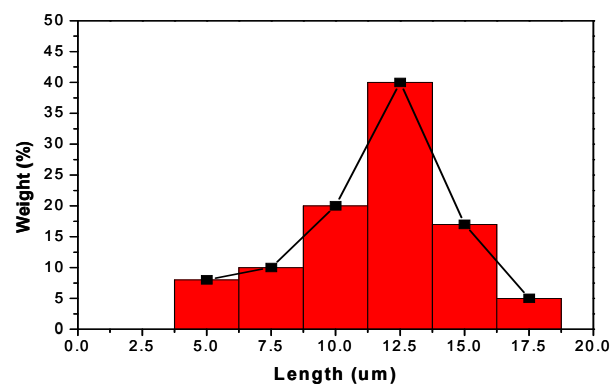

(b)

Figure 2. Purified silver nanowires (AgNWs): (a) scanning electron microscopy image; (b) length distribution of a purified AgNW.

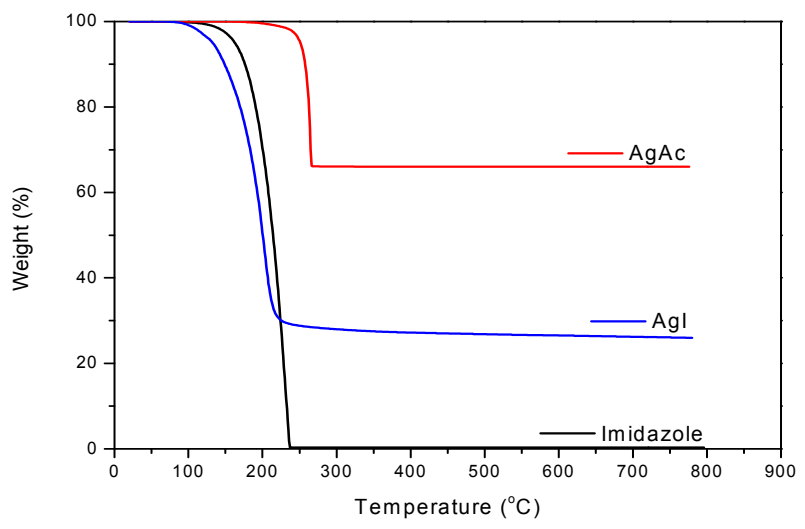

Figure 3. Thermogravimetric analysis thermograms of imidazole, silver-imidazole complex (AgI), and silver acetate $(\mathrm{AgAc})$.

Table 1. Energy-dispersive X-ray spectroscopy data for epoxy/silver nanocomposites cured with the $10 \mathrm{wt} \%$ silver-imidazole complex and the epoxy resin cured with imidazole.

\begin{tabular}{ccccc}
\hline \multirow{2}{*}{ Element } & \multicolumn{2}{c}{$\begin{array}{c}\text { Epoxy Resin Cured with the } \\
\text { Silver-Imidazole Complex }\end{array}$} & \multicolumn{2}{c}{$\begin{array}{c}\text { Epoxy Resin Cured } \\
\text { with Imidazole }\end{array}$} \\
\cline { 2 - 5 } & $\mathbf{W t} \%$ & At \% & Wt \% & At \% \\
\hline C & 67.86 & 75.50 & 69.48 & 75.62 \\
O & 28.85 & 24.09 & 30.52 & 24.38 \\
Ag & 3.29 & 00.41 & 0.00 & 0.00 \\
\hline
\end{tabular}


Figure 4 shows the surface electrical resistivities of the nanocomposites containing AgNWs at various concentrations with the imidazole and silver-imidazole complexes. Generally, the silver-imidazole-cured samples had lower surface electrical resistivities when compared with those of the imidazole-cured samples. Corcione and Maffezzoli measured transport properties of graphite/epoxy composites and characterized them with various theoretical models [29]. As the electrical resistivity of the nanocomposites in Figure 4 showed threshold decrease with increasing AgNW contents, the statistical percolation model was employed in this study. Thus, surface electrical resistivity $(\sigma)$ can be expressed as follows:

$$
\sigma=k\left(P-P_{\mathrm{c}}\right)^{-t}
$$

where $P$ is the volume concentration of $\mathrm{AgNW}, P_{\mathrm{c}}$ the critical volume concentration for the percolation threshold of AgNW, and $t$ the exponent related to the dimensionality of the system. Fittings to Equation (1) were carried out as shown in Figure S2 of Supplementary Materials. Parameters obtained by the fitting are given in Table 2. It was observed that $P_{\mathrm{c}}$ values of the epoxy/AgNW nanocomposite with in situ-formed silver nanoparticles was lower than that of the epoxy/AgNW nanocomposite without the in situ-formed silver nanoparticles. It may be noted that the in situ-formed AgNP exerted a beneficial effect on the epoxy/silver nanocomposites in terms of electrical properties. The in situ-formed AgNPs between AgNWs decreased the interparticle distance, which facilitated the transfer of electrons between the AgNWs and AgNPs. The imidazole-cured samples had higher surface electrical resistivity when compared with those of the silver-imidazole-cured samples with the same AgNW volume fraction. This was due to the absence of silver nanoparticles formed by the in situ process. The anisotropic property, resulting from the characteristic high aspect ratio of the AgNW, was confirmed by the surface electrical resistivity in the imidazole-cured samples. This phenomenon was especially observed in AgNWs at the loading of 6 to $10 \mathrm{vol} \%$. However, it was not observed in AgNWs below $6 \mathrm{vol} \%$ or over $10 \mathrm{vol} \%$. However, the silver-imidazole-cured nanocomposite did not exhibit the anisotropic phenomenon because of the presence of the silver nanoparticles formed by the in situ process. This is an important advantage of the nanocomposites composed of the in situ-formed silver nanoparticles as well as the AgNW. This allows the potential applications of these nanocomposites in devices requiring isotropic electrical properties.

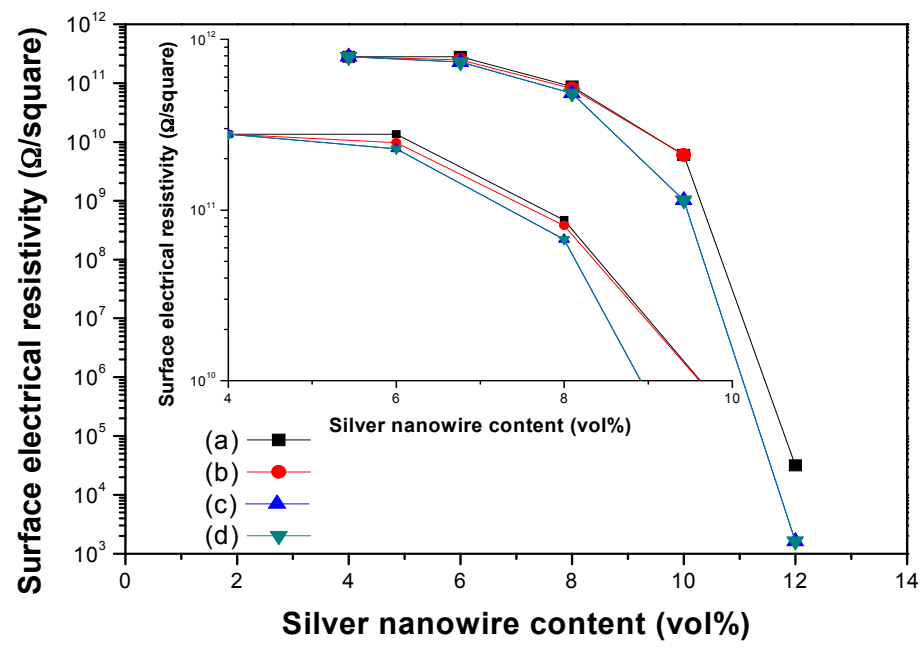

Figure 4. Surface electrical resistivity of the cured epoxy resin containing AgNWs of various concentrations: (a) sample cured with imidazole in the direction of the highest resistivity; (b) sample cured with imidazole in the direction perpendicular to that of (a); (c) sample cured with silver-imidazole complex in the direction of the highest resistivity; (d) sample cured with silver-imidazole complex in the direction perpendicular to that of $(\mathbf{c})$. 
Table 2. Parameter values of the percolation model for samples shown in Figure 4.

\begin{tabular}{ccccc}
\hline Sample & (a) & (b) & (c) & (d) \\
\hline $\boldsymbol{P}_{\mathrm{c}}($ vol \%) & 12.60 & 12.80 & 12.50 & 12.50 \\
$\boldsymbol{t}$ & 4.29 & 4.57 & 4.49 & 4.49 \\
\hline
\end{tabular}

Figure 5 shows the interwire distance in AgNW systems obtained from a geometrical model as described below. The interwire distance is defined as the distance between the two NW surfaces and is useful, as it can be used in conjunction with potential energy curves to determine whether attractive or repulsive energy dominates in a NW particulate system. This information is useful in inferring the stability of NW systems and other surface-related phenomena. Interwire distance has been used as an important parameter for the viscosity estimation of suspensions such as in metallic filler/epoxy resin systems [30]. It also provides useful insights into problems related to formulating suspensions with high filler loadings. At the maximum filler loading, the interwire distance tends to approach a minimum value. Thus, it is useful to understand how the interwire distance affects the physical characteristics of the NW particulates. The model assumes that a parallel piped cell surrounds each NW. It also assumes that the NW volume fraction in a cell is equal to the NW volume fraction throughout the system. Given that the NW is cylindrical, the NW diameter is $d_{\mathrm{w}}$, and the interwire distance of each NW is $d_{\mathrm{i}}$. The volume fraction of the NWs is $\Phi_{\mathrm{w}}$, as given by:

$$
\Phi_{\mathrm{w}}=V_{\mathrm{w}} / V_{\mathrm{u}}
$$

where $V_{\mathrm{w}}$ is volume of NWs in the nanocomposite volume of which is $V_{\mathrm{u}}$, and can be computed as:

$$
\begin{aligned}
& V_{\mathrm{w}}=n \pi\left(d_{\mathrm{w}} / 2\right)^{2} L \\
& V_{\mathrm{u}}=n\left(d_{\mathrm{i}}+d_{\mathrm{w}}\right)^{2} L
\end{aligned}
$$

Equations (2)-(4) are combined to yield $d_{i}$ as a function of $\Phi_{\mathrm{w}}$ as follows:

$$
d_{\mathrm{i}}=d_{\mathrm{w}}\left[\left\{\pi /\left(4 \Phi_{\mathrm{w}}\right)\right\}^{1 / 2}-1\right]
$$

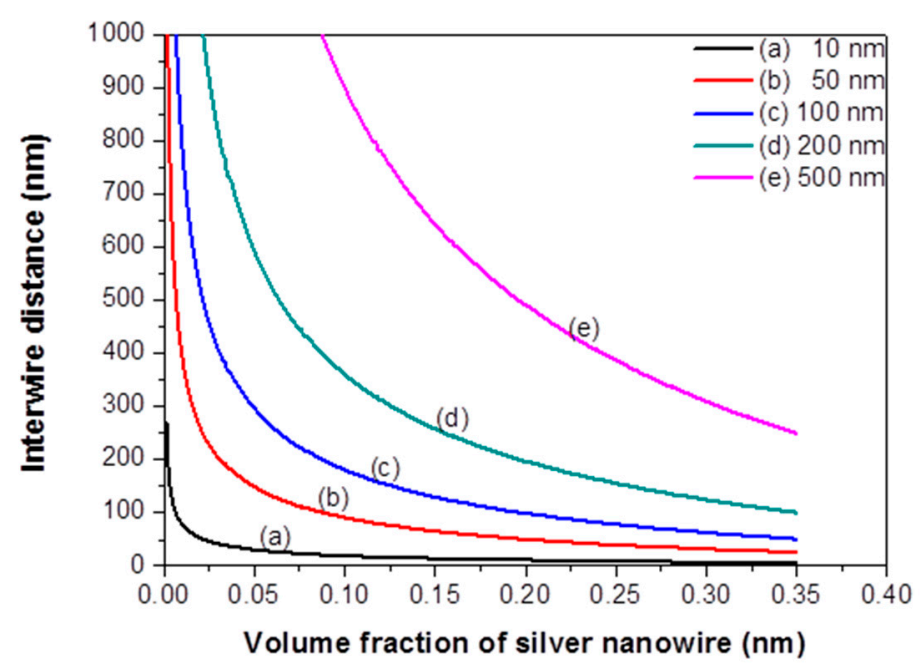

Figure 5. Interwire distances of AgNWs of different diameters: (a) $10 \mathrm{~nm}$; (b) $50 \mathrm{~nm}$; (c) $100 \mathrm{~nm}$; (d) $200 \mathrm{~nm}$; and (e) $500 \mathrm{~nm}$.

The interwire distance for a AgNW of diameter $20 \mathrm{~nm}$ and volume fraction of 10 vol \% was similar to that of the AgNW system with a NW diameter of $200 \mathrm{~nm}$ and a NW volume fraction of $20 \mathrm{vol} \%$. This clearly indicated that an increase in the AgNW diameter increased the amount of 
AgNW dispersed into a medium and formed a high solid loading suspension. However, as the AgNW diameter decreased, the suspension was reduced to clumps. As the interwire distance is very small, it does not allow any more AgNWs to be dispersed into the system, even at a very low AgNW volume fraction. This may be the reason why it is extremely difficult to obtain a high solid loading suspension when the AgNW diameter size is in the nanometer range. The interwire distance in both the $10 \mathrm{vol} \%$ of the AgNW imidazole-cured sample and the silver-imidazole-cured sample in this study should be $144 \mathrm{~nm}$.

The morphology of the cured systems was investigated using SEM. Figure 6a shows the SEM images of the films cured with imidazole with 8 vol \% of AgNWs. No particles are observed in Figure $6 a$. Figure $6 \mathrm{~b}, \mathrm{c}$ show the SEM images of the films cured using $10.0 \mathrm{wt} \%$ of the silver-imidazole complex with $6 \mathrm{vol} \%$ of AgNWs. The in situ-formed nanoparticles were well dispersed in the epoxy resin with AgNWs, and no macroscopic agglomerates were formed. The average particle diameter was $\sim 100 \mathrm{~nm}$. The quality of the AgNW dispersion in the polymer matrix was directly correlated with its effectiveness in improving the properties of the nanocomposites. It is believed that a uniform distribution of the in situ-formed AgNPs in the polymer matrix with AgNWs leads to a relatively high electrical conductivity. The addition of AgNWs in conjunction with the in situ formation of AgNPs facilitated a more uniform dispersion of the NPs in the polymers, thereby reducing anisotropic properties.

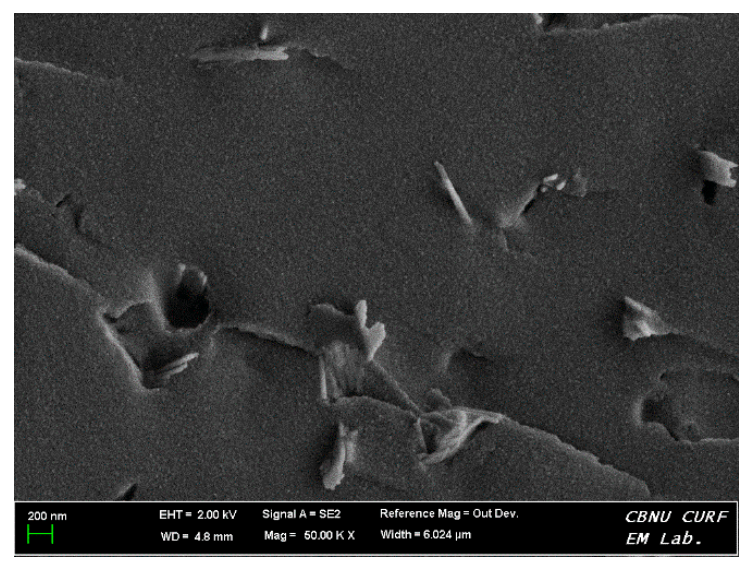

(a)

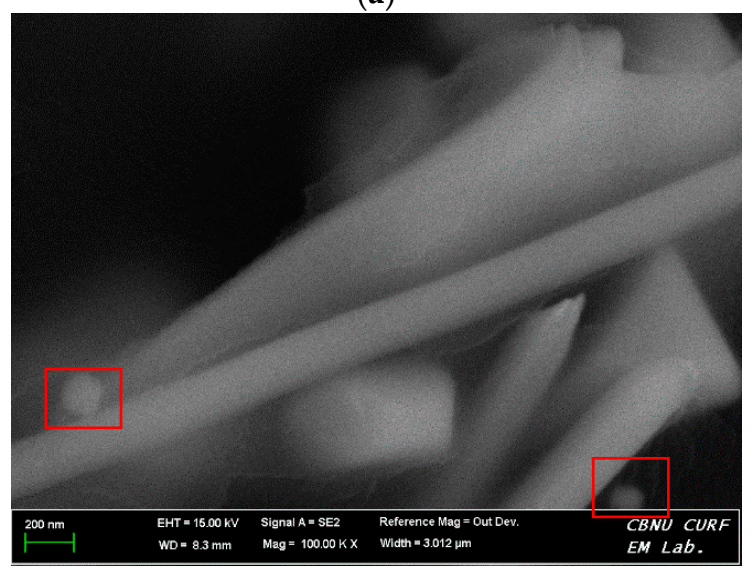

(c)

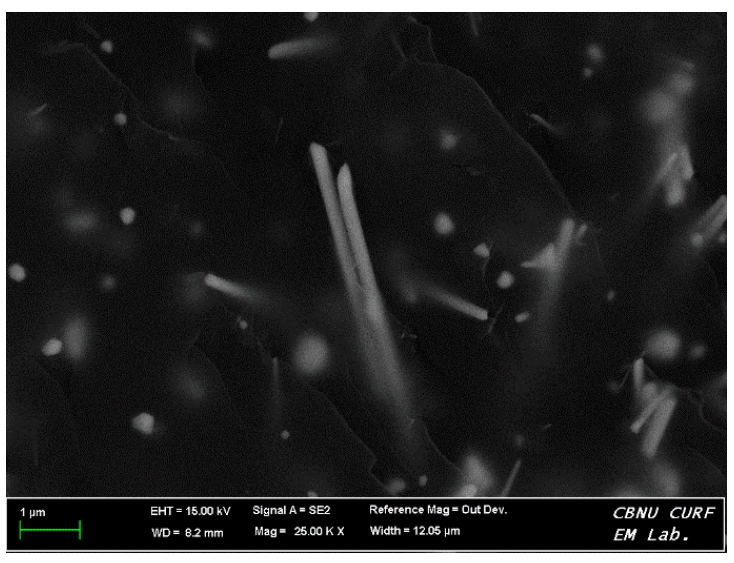

(b)

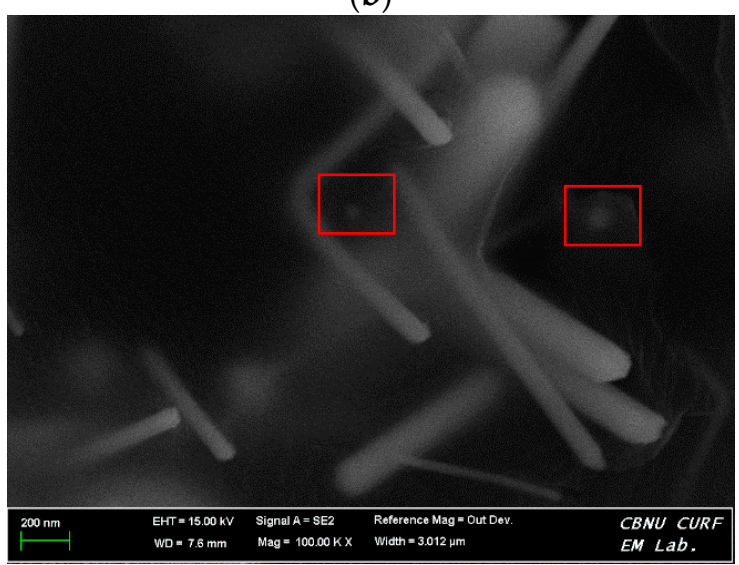

(d)

Figure 6. TEM images of the cured epoxy resin/silver nanocomposites: (a) sample cured with imidazole (scale bar, $200 \mathrm{~nm}$ ); (b) sample cured with $10.0 \mathrm{wt} \%$ of the silver-imidazole complex with $6 \mathrm{vol} \%$ of AgNWs (scale bar, $1 \mu \mathrm{m}$ ); (c) magnified version of the sample in (b) (scale bar, $200 \mathrm{~nm}$ ); (d) sample cured with $10.0 \mathrm{wt} \%$ of silver-imidazole with $8 \mathrm{vol} \%$ of AgNWs (scale bar, $200 \mathrm{~nm}$ ). 


\section{Conclusions}

Epoxy/silver nanocomposites were successfully prepared by the dispersion of AgNWs and the in situ formation of AgNPs via the thermal decomposition of a silver-imidazole complex. The simultaneously released imidazole acted as a catalyst to help cure the epoxy resin. The molar ratio of AgAc to imidazole in the silver-imidazole complex was 1:2. AgNPs were formed in situ during the curing process. The average particle diameter was $100 \mathrm{~nm}$. The in situ-formed AgNPs in the nanocomposites altered the electrical properties of the nanocomposites from anisotropic to isotropic. The nanocomposites of epoxy resin and the AgNWs with isotropic electrical properties caused by the in situ formation of AgNPs are useful as electronic materials in various applications.

Supplementary Materials: The following are available online at www.mdpi.com/2073-4360/8/4/157/s1. Figure S1: DSC thermograms obtained by scanning at heating rate of $10{ }^{\circ} \mathrm{C} / \mathrm{min}$ in $\mathrm{N}_{2}$ gas environment for the epoxy resins containing anhydride type curing agent: (a) without silver-imidazole complex; (b) with 10 wt \% of the silver-imidazole complex. Exothermic heat of cure in (b) was $321.3 \mathrm{~J} / \mathrm{g}$, Figure S2: Fittings to the percolation model Equation (1) for surface electrical resistivity of the samples shown in Figure 4: (a) sample cured with imidazole in direction of the highest resistivity; (b) sample cured with imidazole in the direction perpendicular to that of (a); (c) sample cured with silver-imidazole complex in direction of the highest resistivity; (d) sample cured with silver-imidazole complex in the direction perpendicular to that of (c).

Acknowledgments: It is acknowledged that this work was supported by the Advanced Technical Center (ATC) project of Korea Evaluation Institute of Industrial Technology (KEIT funded by Ministry of Trade, Industry, and Energy (Project No: ATC-10048672) in Korea.

Author Contributions: Gwang-Seok Song and Dai-Soo Lee designed and performed the experiments; Ilho Kang contributed reagents/materials and analyzed the data. Dai-Soo Lee wrote the paper.

Conflicts of Interest: The authors declare no conflict of interest.

\section{References}

1. Yagci, Y.; Sangermano, M.; Rizza, G. Synthesis and Characterization of Gold-Epoxy Nanocomposites by Visible Light Photoinduced Electron Transfer and Cationic Polymerization Processes. Macromolecules 2008, 41, 7268-7270. [CrossRef]

2. Maruo, M.; Acocella, M.R.; Corcione, C.S.; Maffezzoli, A.; Guera, G. Catalytic activity of graphite-based nanofillers on cure reaction of epoxy resins. Polymer 2014, 55, 5612-5615. [CrossRef]

3. Greco, A.; Corcione, C.S.; Maffezzoli, A. Effect of multi-scale diffusion on the permeability behavior of intercalated nanocomposites. J. Membr. Sci. 2016, 505, 92-99. [CrossRef]

4. Lee, H.; Chou, K.; Shih, Z. Effect of nano-sized silver particles on the resistivity of polymeric conductive adhesives. Int. J. Adhes. Adhes. 2005, 25, 437-441. [CrossRef]

5. Jiang, H.; Moon, K.; Li, Y.; Wong, C.P. Surface functionalized silver nanoparticles for ultrahigh conductive polymer composites. Chem. Mater. 2006, 18, 2969-2973. [CrossRef]

6. Lu, J.; Moon, K.; Wong, C.P. Silver/polymer nanocomposite as a high-k polymer matrix for dielectric composites with improved dielectric performance. J. Mater. Chem. 2008, 18, 4821-4826. [CrossRef]

7. Konghua, L.; Lan, L.; Yuanfang, L.; Demin, J. One-step synthesis of metal nanoparticle decorated graphene by liquid phase exfoliation. J. Mater. Chem. 2012, 22, 20342-20352.

8. Ghosh, K.; Maiti, S.N. Mechanical properties of silver-powder-filled polypropylene composites. J. Appl. Polym. Sci. 1996, 60, 323-331. [CrossRef]

9. Sastry, M.; Mayya, K.S.; Bandyopadhyay, K. pH dependent changes in the optical properties of carboxylic acid derivatized silver colloidal particles. Colloids Surf. A Physicochem. Eng. Asp. 1997, 127, 221-228. [CrossRef]

10. Shipway, A.; Lahav, M.; Gabai, R.; Willner, I. Investigations into the Electrostatically Induced Aggregation of Au Nanoparticles. Langmuir 2000, 16, 8789-8795. [CrossRef]

11. Huang, Y.; Duan, X.; Cui, Y.; Lauhon, L.; Kim, K.; Lieber, C. Logic gates and computation from assembled nanowire building blocks. Science 2001, 294, 1313-1317. [CrossRef] [PubMed]

12. Mandal, S.; Gole, A.; Lala, L.; Gonnade, R.; Ganvir, V.; Sastry, M. Studies on the Reversible Aggregation of Cysteine-Capped Colloidal Silver Particles Interconnected via Hydrogen Bonds. Langmuir 2001, 17, 6262-6268. [CrossRef] 
13. Gudiksen, M.S.; Lauhon, L.J.; Wang, J.; Smith, D.C.; Lieber, C.M. Growth of nanowire superlattice structures for nanoscale photonics and electronics. Nature 2002, 415, 617-620. [CrossRef] [PubMed]

14. Sauer, G.; Brehm, G.; Schneider, S. Highly ordered monocrystalline silver nanowire arrays. J. Appl. Phys. 2002, 91, 3243-3247. [CrossRef]

15. Dang, M.; Shen, Y.; Nan, C.W. Dielectric behavior of three-phase percolative $\mathrm{Ni}-\mathrm{BaTiO}_{3} /$ polyvinylidene fluoride composites. Appl. Phys. Lett. 2002, 81, 4814-4816. [CrossRef]

16. Tao, A.; Kim, F.; Hess, C.; Goldberger, J.; He, R.; Sun, Y.; Xia, Y.; Yang, P. Langmuir-Blodgett silver nanowire monolayers for molecular sensing using surface-enhanced Raman spectroscopy. Nano Lett. 2003, 3, 1229-1233. [CrossRef]

17. Sun, Y.; Xia, Y. Langmuir-Blodgett silver nanowire monolayers for molecular sensing using surface-enhanced Raman spectroscopy. Science 2002, 298, 2176-2179. [CrossRef] [PubMed]

18. Sun, Y.; Yin, Y.; Mayers, B.; Herricks, T.; Xia, Y. Uniform Silver Nanowires Synthesis by Reducing $\mathrm{AgNO}_{3}$ with Ethylene Glycol in the Presence of Seeds and Poly(Vinyl Pyrrolidone). Chem. Mater. 2002, 14, 4736-4745. [CrossRef]

19. Yamamoto, M.; Nakamoto, M. Novel preparation of monodispersed silver nanoparticles via amine adducts derived from insoluble silver myristate in tertiary alkylamine. J. Mater. Chem. 2003, 13, 2064-2065. [CrossRef]

20. Sun, Y.; Mayers, B.; Herricks, T.; Xia, Y. Polyol Synthesis of Uniform Silver Nanowires: A Plausible Growth Mechanism and the Supporting Evidence. Nano Lett. 2003, 3, 955-960. [CrossRef]

21. Pothukuchi, S.; Li, Y.; Wong, C.P. Development of a novel polymer-metal nanocomposite obtained through the route of in situ reduction for integral capacitor application. J. Appl. Polym. Sci. 2004, 93, 1531-1538. [CrossRef]

22. Wiley, B.; Herricks, T.; Sun, Y.; Xia, Y. Polyol Synthesis of Silver Nanoparticles: Use of Chloride and Oxygen to Promote the Formation of Single-Crystal, Truncated Cubes and Tetrahedrons. Nano Lett. 2004, 4, 1733-1739. [CrossRef]

23. Luo, C.; Zhang, Y.; Zeng, X.; Zeng, Y.; Wang, Y. The role of poly(ethylene glycol) in the formation of silver nanoparticles. J. Colloid Interface Sci. 2005, 288, 444-448. [CrossRef] [PubMed]

24. Wiley, B.; Xiong, Y.; Li, Z.; Yin, Y.; Xia, Y. Right Bipyramids of Silver: A New Shape Derived from Single Twinned Seeds. Nano Lett. 2006, 6, 765-768. [CrossRef] [PubMed]

25. Sangermano, M.; Yagci, Y.; Rizza, G. In Situ Synthesis of Silver-Epoxy Nanocomposites by Photoinduced Electron Transfer and Cationic Polymerization Processes. Macromolecules 2007, 40, 8827-8829. [CrossRef]

26. Zhang, R.; Moon, K.; Lin, W.; Wong, C.P. Preparation of highly conductive polymer nanocomposites by low temperature sintering of silver nanoparticles. J. Mater. Chem. 2010, 20, 2018-2023. [CrossRef]

27. Tsuji, M.; Hashimoto, M.; Nishizawa, Y.; Tsuji, T. Synthesis of gold nanorods and nanowires by a microwave-polyol method. Mater. Lett. 2004, 58, 2326-2330. [CrossRef]

28. Judd, M.D.; Plunkett, B.A.; Pope, M.I. The thermal decomposition of calcium, sodium, silver and copper(II) acetate. J. Therm. Anal. Calorim. 1974, 6, 555-563. [CrossRef]

29. Corcione, C.E.; Maffezzoli, A. Transport properties of graphite/epoxy composites: Thermal, permeability and dielectric characterization. Polym. Test. 2013, 32, 880-888. [CrossRef]

30. Hao, T.; Riman, R.E. Calculation of interparticle spacing in colloidal systems. J. Colloid Interface Sci. 2006, 297, 374-377. [CrossRef] [PubMed]

(C) 2016 by the authors; licensee MDPI, Basel, Switzerland. This article is an open access article distributed under the terms and conditions of the Creative Commons Attribution (CC-BY) license (http://creativecommons.org/licenses/by/4.0/). 